\title{
CONTRATO, MORAL E POLÍTICA EM ROUSSEAU
}

\author{
Ricardo Monteagudo
}

Unesp-Marília

\begin{abstract}
The aim of this paper is to show how the contract joins with moral and politics in Rousseau's Social contract. The contract denatures and changes human nature when human being becomes social. With this change, moral and politics arouse. Moral is the condition of liberty and politics becomes on the field of consent and rhetoric.
\end{abstract}

Keywords: Rousseau, social contract, contratualism, natural right, political right.

Resumo: 0 objetivo deste artigo é mostrar como o conceito de contrato se articula com a moral e a política no Contrato social de Rousseau. $\mathrm{O}$ contrato desnatura e muda a natureza humana ao torná-la sociável. Coltm essa mudança, surgem a moral e a política. A moral é a condição da liberdade e a política se dá no campo do consentimento e da retórica.

Palavras-chave: Rousseau, contrato social, contratualismo, direito natural, direito político.

\footnotetext{
"Se a compreensão não for acompanhada de um reconhecimento pleno do outro como sujeito, então essa compreensão corre o risco de ser utilizada com vistas à exploração, ao tomar; o saber será subordinado ao poder".
}

(T. Todorov, A conquista da América)

A exposição do contrato social marca o início da apresentação da teoria política de Rousseau no Contrato social. Os principais equívocos do direito natural que interferiam na compreensão do direito político foram 
analisados e cuidadosamente afastados nos capítulos iniciais, que tratam da família (CS, I, 2) ${ }^{1}$, do pretenso direito do mais forte (I, 3), da inconcebilidade da escravidão e de como a guerra já supõe um direito estabelecido (I, 4). O campo está limpo para a nova teoria ${ }^{2}$.

Sabemos assim que a força não cria o direito e que obedecer à força é um ato de necessidade. Sabemos que o homem que renuncia à sua liberdade renuncia à sua qualidade de homem. Estes são dois conceitos-chave para o contrato, que se inicia com uma suposição: "Suponhamos os homens chegando àquele ponto em que os obstáculos prejudiciais à sua conservação no estado de natureza sobrepujam, pela sua resistência, as forças de que cada indivíduo dispõe para manter-se nesse estado. Então, esse estado primitivo já não pode subsistir, e o gênero humano pereceria se não mudasse de modo de vida” (CS, I, 6; ROUSSEAU, 1964, p.360). O homem está no estado de natureza. Num determinado momento, a força do homem para conservar-se é superada pelos obstáculos à sua conservação. A força do homem era maior que a força dos obstáculos e, de uma hora para outra, tornou-se menor. Se isso acontecesse com qualquer outro animal, este animal certamente desapareceria, dada a inferioridade da força e a impossibilidade de criar novas forças. O homem, todavia, tem uma alternativa, que é mudar o modo de vida. Os homens que porventura não mudaram o modo de vida, pereceram. Por outro lado, os que mudaram o modo de vida, transformaram sua relação com a natureza, pois criaram novas forças que lhes permitiram vencer a maior força contrária da natureza. Então, os obstáculos eram maiores do que as forças de cada indivíduo e, por isso, o gênero humano mudou o modo de vida, isto é, todo o conjunto dos indivíduos precisou mudar. Pois bem, no que consistiu esta mudança? "Como os homens não podem engendrar novas forças, mas somente unir e orientar as já existentes, não têm eles outro meio de conservar-se senão formando, por agregação, um

\footnotetext{
${ }^{1}$ As referências à obra Contrato social são indicadas por CS e acompanham em algarismos romanos 0 livre e em arábico o capítulo. O número da página, quando necessário, é o das Oeuvres complètes da Collection Pléiade, conforme a bibliografia.

${ }^{2}$ Há diversas hipóteses para a integração da idéia de pacto no Discurso sobre a desigualdade com 0 pacto social do Contrato social, especialmente devido à concepção de "revolução" que é a mesma nas duas obras (ver coletânea em L'AMINOT, 1994). Cf. SIMÉON, 1977; FORTES, 1976; JOUVENEL, 1978; NASCIMENTO, 1980. Note por outro lado que a idéia de revolução em Rousseau se dissocia da de progresso, cf. BACZKO, 1974, p.111 ss; CASSIRER, 1992 e SOUZA, 2001, p.77. Cf.tb RADICA, 2008 e BERNARDI, 2006, que tomam o conceito de "governo" para fazer esta discussão.
} 
conjunto de forças que possa sobrepujar a resistência, impelindo-as para um só móvel, levando-as a operar em concerto" (idem).

Dessa forma, para vencer os obstáculos, os homens não criaram novas forças, cada indivíduo não pôde criar novas forças do nada. O que os indivíduos fizeram foi unir e orientar as forças já existentes, agregar um conjunto de forças que superasse os obstáculos da natureza. Assim, cada indivíduo uniu suas forças com as dos outros indivíduos, formando juntos, pela soma, uma força maior do que os obstáculos ${ }^{3}$. Este agregado de forças precisa agir em concerto, isto é, a força de cada um configura instrumentos diferentes que contribuem para a maior força do todo. Se tomarmos a metáfora musical do concerto, podemos dizer que cada instrumento contribui melodicamente para a harmonia do todo. Há então uma união das diferentes forças que fortalece o conjunto. Por outro lado, os indivíduos que não se uniram, pereceram. Há aí uma nova questão.

As forças de cada homem se unem às forças de outros homens no estado de natureza e, com isso, o gênero humano muda o modo de vida porque muda a relação de suas forças com o estado de natureza. Entretanto, o estado de natureza impõe aos animais o instinto para orientar suas ações. Ora, o homem não seguiu seu instinto e por isso mudou seu modo de vida. O que permite ao homem não seguir seu instinto é a liberdade, ou melhor, a liberdade é um instinto peculiar ao animal humano. Podemos então dizer que os homens que não agiram livremente ao não se unirem a outros homens, pereceram. Por isso, "a força e a liberdade de cada indivíduo são os instrumentos primordiais de sua conservação”. Assim, o homem livre uniu suas forças às de outros homens livres e juntos superaram os obstáculos da natureza. Entretanto, o comprometimento da força e da liberdade de cada um com a união para salvar o homem não pode condenar o homem, ou melhor, os homens se uniram para se conservar, não podem "prejudicar e negligenciar” sua própria conservação. Ora, não é possível unir-se para não perecer e perecer ao mesmo tempo. Essa união, portanto, que muda o modo de vida do gênero humano, tem uma característica sem a qual a união é absurda: "encontrar uma forma de associação que defenda e proteja a pessoa e os bens de cada associado com toda a força comum, e pela qual cada um,

\footnotetext{
${ }^{3}$ Pela teoria newtoniana, a força é um vetor, então podemos pensar numa soma vetorial e não apenas numa totalização aritmética.
} 
unindo-se a todos, só obedece contudo a si mesmo, permanecendo assim tão livre quanto antes".

Assim, primeiro, o animal humano, ao se tornar homem, não pode mais voltar a ser animal. Segundo, o homem entra com sua pessoa e seus bens na associação que defende e protege sua pessoa e seus bens. Terceiro, a associação cria uma força comum que é maior do que os obstáculos da natureza, motivo pelo qual foi estabelecida. Quarto, cada associado é livre para se unir (embora não o seja para não se unir ${ }^{4}$ ) e precisa permanecer livre na associação. Quinto, a força comum, criada com a liberdade e a força de cada um, precisa preservar a liberdade sem a qual a força comum não existe. Sexto, cada um é livre para se preservar e precisa por isso permanecer livre na associação que o preserva. Sétimo, cada um permanece tão livre quanto antes, porém a força comum precisa persistir para vencer os obstáculos da natureza.

Note com isso que a liberdade mudou, pois, antes da associação, a liberdade de cada um era limitada pela natureza e pelas forças de cada um; na associação, a liberdade de cada um é limitada pela natureza e também pela associação, pelas forças de cada um e também pela força comum ${ }^{5}$. Assim, a mudança no gênero de vida consiste em acrescentar às forças naturais de cada um a força comum da associação, e à liberdade de cada um (que estava por assim dizer adormecida) a liberdade comum da associação. Antes o homem só obedecia a si mesmo, mas não tinha escolha; depois, o homem só obedece a si mesmo e tem consciência de sua liberdade. Em outros termos, o homem permanece tão livre quanto antes porque antes se limitava à natureza física e depois se limita à natureza social.

\footnotetext{
${ }^{4}$ Devido ao amor-de-si, o homem não tem o direito (natural) de se suicidar, assim o homem não é livre para rejeitar a associação e perecer solitariamente no estado-de-natureza. Ao contrário, o homem tem 0 dever de lutar por sua liberdade. Em CS, II, 5: "Pergunta-se como os particulares, não gozando do direito de dispor da própria vida, podem transmitir ao soberano este mesmo direito que não têm". Por outro lado, ninguém tem o "direito de subtrair a liberdade de outrem" (CS, I, 1), então como a associação que cria a liberdade comum poderia ao mesmo tempo subtraí-la antes de criá-la? Seria reduzir o homem à animalidade antes de se tornar um homem.

${ }^{5}$ Há alguns movimentos conceituais no pensamento de Rousseau que parecem hegelianos avant la lettre: a superação (Aufhebung) da liberdade natural em liberdade particular e liberdade pública, mantendo a independência natural e estabelecendo uma dependência moral de forma irreversível, é um deles. Alguns autores chamaram atenção para isso (cf. PARIENNE, 1971; IMBERT, 1997; BESSE 1988; entre outros), mas não convém estender o raciocínio para todo o conjunto do pensamento (como bem mostrou STAROBINSKI, 1991).
} 
Segundo Rousseau, esse contrato é determinado pelo ato de associação e suas cláusulas, "tacitamente mantidas e reconhecidas em todos os lugares" (id.). Trata-se assim de algo universal e necessário, independe portanto do fato e da história ${ }^{6}$.

Há contudo uma ressalva que precisa ser explicada: se o pacto social é violado, "cada um volta a seus primeiros direitos e retoma sua liberdade natural perdendo a liberdade convencional pela qual renunciara àquela” (id.). De um lado, Rousseau introduz a oposição entre liberdade natural e liberdade convencional, mostrando que "permanecer tão livre quanto antes" é na verdade manter uma nova liberdade, uma liberdade que foi criada pela convenção. De outro lado, é preciso compreender a violação do pacto social de duas formas. Primeiro, o ato necessário de associação para vencer a maior força contrária (obstáculos à conservação) no estado de natureza que mudou o modo de vida do gênero humano. Esta primeira associação é inviolável porque interrompe a vida no estado de natureza e introduz o estado social e, com este, a cultura e a história. Segundo, a associação moral e política historicamente constituída. Quando a associação deixa de "proteger e defender a pessoa e os bens de cada associado com toda a força comum” porque a liberdade associada não corresponde mais à união de todos, então o pacto foi violado. Nesse caso, o homem não pode mais voltar a ser o animal humano que era no estado de natureza, mas deixa de ter os direitos e deveres da liberdade convencional e recupera os direitos e deveres de sua liberdade natural, isto é, ele deixa de ter compromisso com a associação e fica livre para criar uma nova associação ${ }^{7}$ do ponto de vista administrativo, como indicado desde o começo do Contrato: "Quando um povo é obrigado a obedecer e o faz, age acertadamente; assim que pode sacudir este jugo e o faz, age melhor ainda, porque, recuperando a liberdade pelo mesmo direito que lha arrebataram, ou tem ele o direito de

\footnotetext{
${ }^{6} \mathrm{Na}$ passagem correspondente a esta do Manuscrito de Genebra (primeira versão do Contrato social), Rousseau insiste que "procura o direito e não disputa pelos fatos" (ROUSSEAU, 1964a, p.297). Em nota ao Contrato da Coleção Pléiade, Robert Derathé afirma que "o contrato social é universalmente válido em direito e não tem seu equivalente no fato" (DÉRATHÉ, 1964, n.5, p.1444). Cf. BACHOFEN, 2002, p.112-5.

${ }^{7}$ Em nota da Pléiade, Derathé cita uma passagem do Contrato (CS, III, 10; ROUSSEAU, 1964, p.422-3) indicando tratar-se aí do direito de rebelião no caso de usurpação do poder soberano (DÉRATHÉ, 1964, n.6, p.1444): "à l'instant que le gouvernement usurpe la souveraineté, le pacte social est rompu, et tous les simples citoyens, rentrés de droit dans leur liberté naturelle, sont forcés mais non pas obligés d'obéir".
} 
retomá-la ou não o tinham de subtraí-la” (CS, I, 1). Rousseau então apenas reafirma a obrigação moral de lutar pela liberdade.

Feita a ressalva, Rousseau volta a tratar do contrato mostrando que este se reduz a uma única cláusula: "alienação total de cada associado, com todos os seus direitos, à comunidade toda, porque, em primeiro lugar, cada um dando-se completamente, a condição é igual para todos, e, sendo a condição igual para todos, ninguém se interessa por torná-la onerosa para os demais" (CS, I, 6). Como cada um dá tudo o que tem, a condição de todos é igual. Institui-se assim a igualdade moral independentemente das desigualdades físicas, pois as pessoas são fisicamente diferentes, os bens que cada um dá são também diversos, no entanto, cada um "dando-se a todos não se dá a ninguém”. Cada indivíduo dá sua liberdade natural e ganha de volta um equivalente, a liberdade moral, e ainda a força comum para conservar o que tem. Daí a essência do contrato social: "Cada um de nós põe em comum a pessoa e todo o seu poder sob a direção suprema da vontade geral, e recebemos, enquanto corpo, cada membro como parte indivisível do todo" (I, 6).

O final do capítulo sobre o pacto apresenta uma terminologia que surpreende e precisa ser comentada. Rousseau define a pessoa pública formada como Cidade e República, ou Corpo Político, chamado de Estado quando passivo, soberano quando ativo e potência quando comparado a seus semelhantes. Se retornarmos à perspectiva que abordamos, a saber, a de que o contrato mudou o modo de vida do gênero humano porque o animal humano se tornou homem, então surge aí uma lacuna entre o estabelecimento de um corpo moral e o de um Corpo Político - por isso é tão importante para Rousseau que a comunidade se institua por um contrato, mas o governo não. De fato, esta lacuna só se apresenta caso vinculemos, à maneira hobbesiana, a existência de um Corpo Político à de um governo ${ }^{8}$. Nesse caso, Corpo Político seria apenas o Estado que tem um governo instituído. Entretanto, trata-se aqui apenas do povo, independentemente da

${ }^{8}$ ROUSSEAU escreveu um capítulo especialmente para mostrar que não há contrato entre o povo e seus chefes, em CS, III, 16; embora as críticas a GROTIUS já deixassem clara esta hipótese, cf. CS, I, 5: "Un peuple, dit Grotius, peut se donner à un roi. Selon Grotius un peuple est donc un peuple avant de se donner à un roi. Ce don même est un acte civil, il suppose une délibération publique. Avant donc que d'examiner l'acte par lequel un peuple élit un roi, il serait bon d'examiner l'acte par lequel un peuple est un peuple. Car cet acte étant nécessairement antérieur à l'autre est le vrai fondement de la société". 
forma de governo9 , ou, conforme indicação anterior numa crítica a Grotius: "um povo é povo antes de ter rei" (CS, I, 5). Nesse sentido, por exemplo, os caraíbas da Venezuela são um povo, e os índios do artigo "Sociedade contra o Estado" (CLASTRES, 1988), do antropólogo Pierre Clastres, também, ou seja, segundo Clastres eles não têm Estado porque não têm concentração de poder, não têm governo, mas segundo a terminologia de Rousseau, se eles são um povo então são um Corpo Político, e portanto um soberano e um Estado, embora sem governo. Rousseau intitularia o artigo de Clastres como "Sociedade contra o governo" 10 .

Vimos que o Contrato social se abre pelo exame da possibilidade de existência de alguma regra de administração legítima e segura, isto é, se pode haver algum governo que não seja arbitrário, donde a importância da ausência do governo na terminologia adotada com a teoria do pacto social. Rousseau descreve as condições do corpo moral e em seguida o caracteriza como corpo político. Como vimos, esta é a questão principal, o contrato institui a moralidade e não o governo, por isso um corpo moral é um corpo político antes de ter um governo. Ademais, a instalação de um governo não

${ }^{9}$ O governo e suas formas é tratado no livro III do Contrato, após a consideração da lei, do legislador e da opinião pública.

${ }^{10} \mathrm{P}$. CLASTRES mostra que algumas tribos primitivas recusam a concentração do poder e por isso não constituíram um "Estado": "O Estado, dizem, é o instrumento que permite à classe dominante exercer sua dominação violenta sobre as classes dominadas, (...) Por conseguinte, a estrutura da sociedade - a divisão em classes - deveria preceder a emergência da máquina estatal" (CLASTRES, 1988, p.142). Como se vê, a idéia de Estado indicada no título do artigo pressupõe uma sociedade em que o exercício de mando já está estabelecido e, como este exercício não existe entre algumas tribos indígenas conhecidas, então estas tribos rejeitam a formação de algo que se assemelhe a esta noção de Estado: "A tribo não possui um rei, mas um chefe que não é chefe de Estado. (...) Simplesmente o chefe não dispõe de nenhuuma autoridade, de nenhum poder de coerção, de nenhum meio de dar uma ordem. 0 chefe não é um comando, as pessoas da tribo não têm nenhum dever de obediência. $O$ espaço da chefia não é o lugar do poder e a figura (mal denominada) do 'chefe' selvagem não prefigura em nada aquela de um futuro déspota" (p.143). O interesse de Clastres é ter encontrado uma comprovação histórica (ou fatual) para a hipótese do Discurso sobre a desigualdade, (por exemplo, "Por que alguns desejaram proclamar um dia isto é meu? ...", p.142). Todavia, nosso objetivo aqui é mostrar que Rousseau define o vocábulo Estado mais como Nação (ou como uma comunidade de costumes uniformes) do que como uma instituição caracterizada pela dominação (pela luta de classes). Toda sociedade, para existir, tem costumes e portanto já se caracteriza como povo, como soberano. Se tomarmos o esquema do Discurso sobre a desigualdade, que divide a história hipotética em cinco fases, a saber, primeiro estado de natureza (independência), segundo estado de natureza (sociabilização), sociedade civil (propriedade), sociedade política (pacto dos ricos) e despotismo (governo arbitrário), então o segundo estado de natureza já é um Estado pela definição proposta por Rousseau no Contrato $(\mathrm{CS}, \mathrm{I}, 6)$, mas só a sociedade política instituída pelo pacto dos ricos será um Estado pela definição acima apresentada por Clastres. 
se dá por um novo contrato, ou pelo menos não no mesmo molde do primeiro $^{11}$.

O governo é um corpo intermediário entre o soberano e o Estado, só se torna necessário em função de problemas na relação entre o soberano e o Estado e é por isso necessariamente antecedido pelo legislador, que por sua vez só pode ser entendido a partir das dificuldades na explicitação e na compreensão das leis. Ora, como quem faz as leis é o cidadão e quem obedece é o súdito, e como o cidadão e o súdito são a mesma pessoa numa dupla relação com o soberano e com o Estado, então o legislador surge como solução para as dificuldades dessa dupla relação. Por isso, para que se compreenda a função e os limites do governo, as condições para sua instituição legítima e as causas de sua degeneração em instituição arbitrária, é preciso antes apresentar o soberano, a lei e o legislador, nesta ordem.

Depois de discutir os problemas do direito natural, Rousseau vai enfrentar suas consequências na definição de soberania. Estes são os temas do livro II para introduzir o governo, tema do livro III. O livro I, por sua vez, mostra por que a moralidade, apesar de ser sagrada, não é um direito natural mas um direito convencional, e por que o corpo moral, apesar de convencional, não é arbitrário mas legítimo.

Os dois capítulos que seguem a descrição do contrato (CS, I, 7 e 8) tratam, respectivamente, do soberano ainda sem governo e da moralidade incorporada ao homem natural, ou seja, tratam do mesmo corpo coletivo instituído, num capítulo como corpo político e noutro como corpo moral, ou ainda, o mesmo corpo de um ponto de vista político e de um ponto de vista moral.

O corpo moral instituído pela associação dos homens se chama Estado quando passivo e soberano quando ativo, e seus membros se chamam cidadãos quando participam do soberano e súditos quando se submetem às leis do Estado. Assim, o soberano é a vontade geral que une o corpo, e o Estado é o conjunto de súditos obedientes à lei caracterizando o corpo unido. O soberano e o Estado são o mesmo corpo visto de dois pontos de vista, o primeiro delibera e age, o segundo é o resultado da decisão e da ação.

\footnotetext{
11 Um artigo importante sobre o contratualismo moderno que relaciona contrato, soberania e governo na perspectiva de Hobbes, Grotius, Pufendorf e Rousseau é SPITZ, 1988. Em relação à economia, LARRÈRE, 1992, capítulo 1.
} 
Como normalmente o governo executa as decisões do soberano, é comum confundir suas funções, apesar de todo o cuidado que Rousseau tomou para manter a distinção. De fato, Rousseau dá o nome de contrato à instituição do soberano e do Estado, mas outros teóricos ${ }^{12}$ consideram que contrato é a instituição do Estado e do governo, isto é, a transferência de soberania do povo para o governo. Ora, todos, de Platão a Locke passando por Aristóteles, Grotius, Espinosa e Pufendorf entre outros - exceto Hobbes - consideram o homem naturalmente sociável, o que os leva a considerar a Carta Magna do Estado como um contrato do governo com o povo. Hobbes, o único que "viu muito bem o defeito de todas as definições do direito natural" (ROUSSEAU, 1964b, p.153), também considera que a constituição do Estado é a instituição do governo por um pacto de submissão dos homens ao governo para garantir a paz ${ }^{13}$. Rousseau, por sua vez, a exemplo de Hobbes, retira a sociabilidade da natureza humana e a devolve por meio de um pacto, mas, ao contrário de Hobbes ${ }^{14}$, não admite a transferência de soberania. $\mathrm{O}$ pacto cria o soberano de tal forma que este não pode ser representado sem se auto-anular. Com isso, o governo (republicano) deve obedecer o soberano, portanto deve respeitar as leis e jamais se considerar acima delas. Essa distinção entre governo legítimo e governo arbitrário já está presente no Discurso sobre a desigualdade ${ }^{15}$.

Os outros teóricos dissociam o soberano e o Estado, enquanto Rousseau vê o mesmo corpo sob dois aspectos diferentes. Acontece a mesma relação com o cidadão e o súdito, na qual cada indivíduo estabelece uma

${ }^{12}$ Como o contrato muda a natureza humana e é irreversível (cf. CS, I, 8) e, por outro lado, o governo não é instituído por contrato (cf. CS, III, 16), então, já que todos os outros autores consideram o governo oriundo de contrato, podemos caracterizar Rousseau como anti-contratualista, ou, pelo menos, como um contratualista muito peculiar.

${ }^{13} \mathrm{Cf}$. Leviatã, cap. 17. O que é interessante no pacto hobbesiano é que seu objetivo é a paz e obriga somente o "foro externo", não interfere no "foro ínterno" do cidadão (embora as leis naturais criem 0 desejo pela paz, cf. op.cit. cap. 15 in fine). Rousseau, ao contrário, vai procurar meios para comprometer a consciência de cada um com o exercício de cidadania, donde a interdependência de política e moral.

14 Para Hobbes, o governo enquanto actor representa o povo, que é o author. Cf. TINLAND, 1988, p.125 ss, TUCK, 2001, p.91. Por outro lado, Renato J.Ribeiro mostra como para Hobbes a idéia de um contrato que desnature o homem é inconcebível (RIBEIRO, 1984, pp.21-2).

${ }_{15}$ No Discurso sobre a desigualdade, a terceira "revolução da desigualdade" é a conversão do governo legítimo em governo arbitrário (ROUSSEAU, 1964b, p.190-1). O governo oriundo da segunda revolução (pacto dos ricos) era legítimo porque estabeleceu, digamos, um "estado de direito". Só o Contrato social permite apoiar a legitimidade não apenas na lei (positiva) mas também na justiça proveniente das condições da sociabilização do homem (ou do contrato social), cf. MONTEAGUDO, 2004. 
dupla relação com o corpo político (com a associação). Este indivíduo é parte da associação e constitui o corpo político como parte ativa, contribuindo com o soberano, e como parte passiva, obedecendo ao Estado: duas perspectivas na relação do particular com o público, daí a dupla relação.

$\mathrm{O}$ homem se associa alienando sua liberdade natural e recebendo em troca uma liberdade convencional por meio da qual estabelece uma dupla relação com o corpo coletivo instituído. Assim como o animal humano se torna homem, pois a associação "substitui o instinto pela justiça e dá a suas ações a moralidade que elas não tinham” (CS, I, 8), a liberdade natural se torna liberdade moral e o homem adquire consciência de sua liberdade e espiritualidade em sua alma. A instituição da associação que estabelece uma dupla relação do homem com o corpo convencional, como cidadão e como súdito, cria duas formas de liberdade convencional: a liberdade política é a liberdade do cidadão e a liberdade moral, a liberdade do súdito ${ }^{16}$. De um lado, a cidadania se caracteriza pela vida política ativa (vita activa) ${ }^{17}$ e, de outro, a obediência às leis quando não há risco de punição é um problema de consciência pessoal, portanto um problema moral.

O contrato social, e a vontade geral que dele resulta e que o condiciona, garante ao soberano que ele seja sempre o que deve ser, pois sem a vontade geral não há soberano nem nada do que o corpo coletivo garante, como liberdade moral e consciência. Por isso, o soberano é a condição da liberdade ${ }^{18}$, e, deste ponto de vista, sua violação implicaria sua destruição, caso não houvesse meios para mediar as diversas formas possíveis de consentimento. Além disso, o soberano nunca prejudica seus membros, nem coletivamente nem particularmente, porque ele só existe por meio deles. A partir daí, podemos fazer uma analogia para compreendermos o problema que deverá ser enfrentado pelo soberano e que está se configurando: o soberano está para os associados assim como a natureza está para os animais, então a lei do soberano (ou vontade geral) está para as vontades dos

\footnotetext{
${ }^{16}$ Basicamente caracterizo como liberdade política a "dupla relação" do cidadão e do súdito (cf. CS, I, 7: "compromisso recíproco entre o público e os particulares") e como liberdade moral a consciência implicada em todo ato de liberdade (cf. CS, I, 8: a justiça substitui 0 instinto e "dá às suas ações a moralidade que antes Ihes faltava").

${ }^{17}$ Embora sem referir-se a Rousseau, H.Arendt comenta a origem desta questão na Antiguidade e sua metamorfose ao longo da história (ARENDT, 2000).

${ }_{18}$ A concepção de soberania é reinventada por Rousseau, já que toda a tradição é revista, cf. BERNARDI, 2006, capítulo 4.
} 
particulares assim como a lei da natureza está para as vontades dos animais (ou instinto). Ora, os animais não podem desobedecer a lei natural porque seu instinto não é livre, mas os homens podem desobedecer a vontade geral porque são livres. Então a natureza impõe sua vontade aos animais por necessidade, mas o soberano só impõe a vontade geral aos homens por liberdade, ou seja, por consciência, por moralidade.

O raciocínio parece circular porque efetivamente aí está a origem do problema: o homem no estado de natureza (animal humano) só venceu os obstáculos da natureza prejudiciais à sua conservação porque mudou seu modo de vida, isto é, foi livre para resistir à natureza e não seguir seu instinto animal. Nesse momento, o animal humano deveria ter perecido, mas ao invés disso, tornou-se homem criando o soberano. Assim, o soberano só existe porque o homem é livre. Se o soberano se impusesse aos homens como a natureza se impõe aos animais, então o soberano seria natural e o homem não poderia usar sua liberdade contra a natureza e pereceria. Pelo mesmo motivo, o homem pode usar sua liberdade contra o soberano. Por isso, Rousseau diz que "se a alienação é sem reservas, a união é tão perfeita quanto pode ser".

A alienação da liberdade natural transforma o animal humano em homem dando-lhe liberdade moral e consciência, mas o soberano não pode se impor da mesma forma que a natureza. Por isso, a dupla relação do homem com o soberano é tão complexa: o súdito é moralmente obrigado a obedecer a lei, mas, como é naturalmente livre, pode se desobrigar de obedecer a lei. Os particulares podem não seguir seus compromissos "considerando o que deve[m] à causa comum como uma contribuição gratuita” (CS, I, 7). Ora, como isso pode arruinar o soberano, aquele que desobedecer precisa "ser forçado a ser livre", isto é, precisa reconhecer a moralidade de suas ações. A existência dos membros do soberano é "absoluta e naturalmente independente", mas é moralmente dependente, já que o homem tem consciência moral. "Considerando a pessoa moral que constitui o Estado como um ente de razão, porquanto não é um homem, ele desfrutará dos direitos do cidadão sem querer desempenhar os deveres de súdito" (id.) - ora, a pessoa moral do Estado não é um ser natural mas é um ser real, não é apenas um ser de razão, pois não é mera fantasia ou quimera 
especulativa, mas é um ser real graças ao qual o homem tem consciência, não é algo indiferente àquele que pensa, mas constitutivo de seu ser ${ }^{19}$.

Dessa forma, o soberano precisa preservar-se desse desajuste entre a liberdade moral e a liberdade política. O soberano precisa "encontrar meios para assegurar a fidelidade dos súditos” (id.). Ora, quais são os meios de que dispõe o soberano com esse objetivo? Como o soberano não é um ser natural, estes meios também não podem ser naturais. Como pode o soberano forçar o súdito desobediente a ser livre? Segundo Rousseau, esse é "o artifício e o jogo de toda máquina política”. Algo para o qual o direito natural não é suficiente e a partir do qual o direito político é necessário. $O$ uso da força comum pode impedir a ruína do corpo político e forçar o súdito à liberdade, mas assim como a força não cria o direito, a força comum pode não atingir a consciência do súdito. Ele então obedeceria por necessidade, enquanto forçado a obedecer, e não por consciência, isto é, por moralidade, por liberdade. Por isso, a força não é o meio (mais) adequado. Qual seria? Como atingir a consciência? A força é um dos meios do jogo político, mas é certamente ineficaz para a consciência. Não basta vencer, é preciso convencer, ou melhor, "conduzir sem violência e persuadir sem convencer" (CS, II, 7). Já que a força é insuficiente, a política é o jogo da retórica eficaz. O critério de eficácia é a conservação do soberano.

\footnotetext{
19 Para Rousseau, "ser de razão" é produto de especulação abstrata e sofisticada ao passo que "ser moral" é a condição de intersubjetividade criada pelo contrato social sem a qual o homem não pode desenvolver consciência. Como 0 ser moral é convencional, então não é natural, mas é real porque "serve de base a todos os direitos" (CS, I, 9). Veja: "O direito do primeiro ocupante, embora mais real do que 0 do mais forte, só se torna um verdadeiro direito depois de estabelecido o de propriedade" (idem). Dessa forma, o direito é "mais" real, ou seja, a relação dos homens entre si e com as coisas ao criar direitos é real mesmo quando não é natural - outras passagens nos permitem esta conclusão, especialmente na discussão sobre o direito de guerra (seja no fragmento "Estado de guerra", ROUSSEAU, 1964c, p.601-12, seja no rascunho recém descoberto Princípios do direito de guerra, ROUSSEAU, 2008) e no capítulo 2 do Manuscrito de Genebra intitulado "Sociedade geral do gênero humano" (ROUSSEAU, 1964a, p.281-9).
} 


\section{REFERÊNCIAS}

ROUSSEAU, Jean-Jacques. Contrat social. In: Oeuvres completes, tome III. Collection "Pléiade". Paris, Gallimard, 1964.

. Manuscrit de Génève (première version du Contrat). In: Oeuvres complètes, tome III. Collection "Pléiade". Paris, Gallimard, 1964a.

. Discours sur l'inégalité. In: Oeuvres complètes, tome III. Collection "Pléiade". Paris, Gallimard, 1964b.

. Fragmentos. Estado de guerra. In: Oeuvres complètes, tome III. Collection "Pléiade". Paris, Gallimard, 1964c.

Contrato social. Discurso sobre a desigualdade. In: Obras. Coleção "Os Pensadores”. São Paulo, Abril, 1979.

Principes du droit de la guerre. Écrits sur la paix perpétuelle. Paris, Vrin, 2008.

BACHOFEN, B. La condition de la liberté: Rousseau, critique des raisons politiques. Paris, Payot \& Rivages, 2002.

BACZKO, B. Rousseau, solitude et communauté. Paris, Mouton, 1974.

BERNARDI, Bruno. La fabrique des concepts: recherches sur l'invention conceptuelle chez Rousseau. Paris, Honoré Champion, 2006.

BESSE, G. Contradiction et altération chez Jean-Jacques Rousseau et l'apprentissage de l'humanité. Paris, Éditions Sociales, 1988.

CASSIRER, E. Filosofia do iluminismo. Campinas, EdUnicamp, 1992.

DÉRATHÉ, Robert. Introduction et notes. In: Oeuvres complètes, tome III. Collection "Pléiade". Paris, Gallimard, 1964.

FORTES, L. R. S. Rousseau: Da Teoria à Prática. São Paulo, Ática, 1976.

HOBBES, T. Leviatã. Coleção "Os Pensadores”. São Paulo, Abril, 1979.

IMBERT, F. Contradiction et altération chez Jean-Jacques Rousseau. Paris, L'Harmattan, 1997.

JOUVENEL, B. Essai sur la politique de Rousseau. In: ROUSSEAU. Du contrat social. Paris, Hachette/Pluriel, 1978.

L'AMINOT, T. (org.). Politique et révolution chez Jean-Jacques Rousseau. Oxford, Voltaire Foundation, 1994.

LARRÈRE, C. L'invention de l'économie au XVIIle siècle. Paris, Puf, 1992.

MONTEAGUDO, R. Opinião pública e legitimidade. In: Fragmentos de cultura, vol.14, núm.4. Goiânia, editora da UCG, 2004. 
NASCIMENTO, M. M. do. Rousseau, a Revolução e os nossos Fantasmas. In: Discurso, núm.13. São Paulo, 1980.

PARIENNE, J.C. Le Rationalisme Appliqué de Rousseau. In: Hommage à Jean Hyppolite. Paris, PUF, 1971.

RADICA, G. L'histoire de la raison: anthropologie, morale et politique chez Rousseau. Paris, Honoré Champion, 2008.

RIBEIRO, R. J. Ao leitor sem medo. São Paulo, Brasiliense, 1984.

SIMÉON, J.P. La démocratie selon Rousseau. In: ROUSSEAU. Du contrat social. Paris, Seuil, 1977.

SOUZA, M. G. Ilustração e história - o pensamento sobre a história no iluminismo francês. São Paulo, Discurso, 2001.

SPITZ, J.-F. La théorie du double contrat chez Grotius et Pufendorf. In: Cahiers de philosophie politique et juridique, núm.11. Caen, Presses Universitaires de Caen, 1988.

STAROBINSKI, J. A transparência e o obstáculo, seguido de Sete ensaios sobre Rousseau. Trad.Maria Lúcia Machado. São Paulo, Companhia das Letras, 1991.

TINLAND, F. Droit naturel, loi civile et souveraineté à l'époque classique. Paris, PUF, 1988.

TUCK, R. Hobbes. São Paulo, Loyola, 2001.

E-mail: rmonteag@uol.com.br

Recebido: 02/2010

Aprovado: 03/2010 